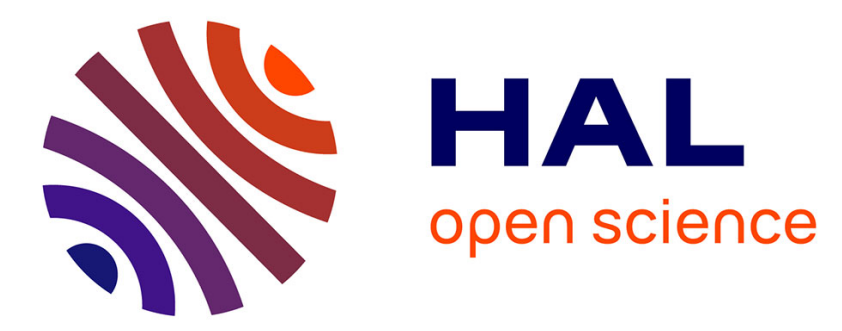

\title{
Magnet Shape Optimization to Reduce Pulsating Torque for a Five-Phase Permanent-Magnet Low-Speed Machine Franck Scuiller
}

\section{To cite this version:}

Franck Scuiller. Magnet Shape Optimization to Reduce Pulsating Torque for a Five-Phase Permanent-Magnet Low-Speed Machine. IEEE Transactions on Magnetics, 2014, 50 (4), pp.1-9. 10.1109/TMAG.2013.2287855 . hal-01060089

\section{HAL Id: hal-01060089 \\ https://hal.science/hal-01060089}

Submitted on 2 Sep 2014

HAL is a multi-disciplinary open access archive for the deposit and dissemination of scientific research documents, whether they are published or not. The documents may come from teaching and research institutions in France or abroad, or from public or private research centers.
L'archive ouverte pluridisciplinaire HAL, est destinée au dépôt et à la diffusion de documents scientifiques de niveau recherche, publiés ou non, émanant des établissements d'enseignement et de recherche français ou étrangers, des laboratoires publics ou privés. 


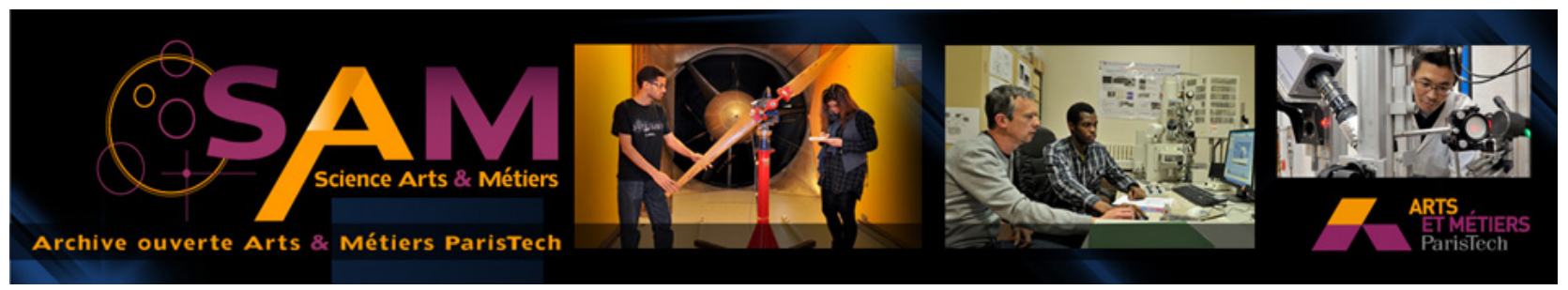

Science Arts \& Métiers (SAM)

is an open access repository that collects the work of Arts et Métiers ParisTech researchers and makes it freely available over the web where possible.

This is an author-deposited version published in: http://sam.ensam.eu

Handle ID: .http://hdl.handle.net/10985/8440

\section{To cite this version :}

Franck SCUILLER - Magnet Shape Optimization to Reduce Pulsating Torque for a Five-Phase Permanent-Magnet Low-Speed Machine - IEEE Transactions on Magnetics - Vol. 50, n 4, p.1-9 2014 


\title{
Magnet shape optimization to reduce pulsating torque for a 5-phase PM low speed machine
}

\author{
Franck Scuiller, Member, IEEE
}

\begin{abstract}
Five-phase Surface-Mounted Permanent Magnet (SMPM) machines can inherently produce a smooth electromagnetic torque which can be increased when using third harmonic current injection. To really take advantage of these characteristics, the rotor magnets can be shaped in order to obtain a back-emf with large third harmonic term. This is the scope of the paper. For the design specifications of a low speed marine propulsion machine, the following objective must be achieved: to significantly mitigate the pulsating torque without reducing the average torque bearing in mind the solution where the rotor is made with full pole-pitch magnets. An analytical field computation, called equivalent coil method, is developed in order to quicly explore the magnet geometries. Thus a procedure to optimize small trapezoid notches at the surface of the pole magnets is performed. Referring to the classical fully pole-pitch magnet shape, the solution found allows a substantial reduction of the pulsating torque without reducing the torque density. Furthermore, with regard to an equivalent three-phase machine, for the same copper losses, the average torque of the optimized five-phase machine can be potentially higher if the third harmonic current injection is implemented.
\end{abstract}

Index Terms-Analytical models, cogging torque, multi-phase machine, permanent magnet machine.

\section{INTRODUCTION}

Multi-phase motors are widely used in electrical marine propulsion for reasons such as reliability, smooth torque and distribution of power [1]. In case of direct-drive, the low rotating speed makes the reduction of ripple torques of critical importance thus justifying the choice of a surface-mounted PM rotor (not rotor saliency). Supplied with a Pulse Width Modulation (PWM) Voltage Source Inverter (VSI), the machine can be controlled to improve the average torque or the efficiency with reference to classical sinusoidal control [2]. To take advantage of this characteristic, the machine can be designed to obtain a particular back-emf spectrum which can be achieved with specific winding distribution and magnet layer characteristics [3]. This magnet shape adaptation can be studied using the multimachine theory. This approach points out the opportunity of using the third space harmonic to enlarge the torque without increasing the pulsating torque. Therefore this paper focuses on the magnet shape adaptation for a five-phase machine.

Numerous papers deal with magnet shape adaptation for three-phase PM machines [4], [5]. With a five-phase machine, since it is possible to increase the torque by using the third space harmonic, the magnet shape adaptation is different. In [6], a particular magnet shape for a five-phase machine is introduced. For the design specifications of a marine propulsion

F. Scuiller is with the Research Institute of Naval Academy, BCRM Brest - EN/GEP CC 600 - 29240 BREST Cedex 9 - FRANCE (e-mail: franck.scuiller@ieee.org) machine, the magnet shape is manually determined without any optimization procedure. The proposed trapezoid magnet shape allows to substantially reduce the pulsating torque referring to the solution where the rotor is made with full polepitch magnets. Unfortunately, the reduction of the magnets volume adversely affects the torque density that is lowered. In the present paper, it is intended to optimize the magnet layer characteristics to reduce the pulsating torque without decreasing the torque density. To reach this goal, the basic idea consists in making small notches on the magnet surface. In practice, to explore these solutions, quite an accurate analytical field computation is necessary.

In the first part, the five-phase machine design goals are explained using the multimachine theory. The opportunity to achieve these design requirements by adapting the pole magnets characteristics is pointed out. The classical magnet pole designs are then reviewed. An analytical representation of an SMPM machine, so-called equivalent coils method, is then described: its applicability to estimate the flux density for large air gap machine is discussed. In the last part, with regard to the design specifications of a marine propulsion machine, the magnet shaping optimization problem is formulated and the results are reported: the enhancements in terms of pulsating torque reduction and torque density are estimated with the analytical method and finite-element analysis (FEA).

\section{FIVE-PHASE MACHINE DESIGN GOALS}

\section{A. Multi-machine decomposition of a five-phase machine}

A multiphase machine is difficult to study owing to its numerous inherent magnetic couplings. The multimachine modeling [7] enables a systematic study of this system with the particularity of taking into account the whole space harmonics. This approach is convenient for non-salient machines such as surface-mounted PM machines. According to this theory, a wye-coupled five-phase machine behaves as a set of two two-phase virtual machines denoted M1 and M2 that are magnetically independent but electrically and mechanically coupled. Each virtual two-phase machine is characterized by its own cyclic inductance (denoted $\lambda_{1}$ and $\lambda_{2}$ ) and back-emf. Each virtual machine is associated with a particular family of space harmonics:

- M1 machine is sensitive to $1^{s t}, 9^{t h},(10 k \pm 1)^{t h}$ harmonics

- M2 machine is sensitive to $3^{r d}, 7^{t h},(10 k \pm 3)^{t h}$ harmonics

As M1 machine is sensitive to the fundamental, M1 is called Main Machine and M2 is called Secondary Machine. Fig. 1 gives a synthetic view of the multi-machine decomposition of a wye-coupled five-phase machine. 


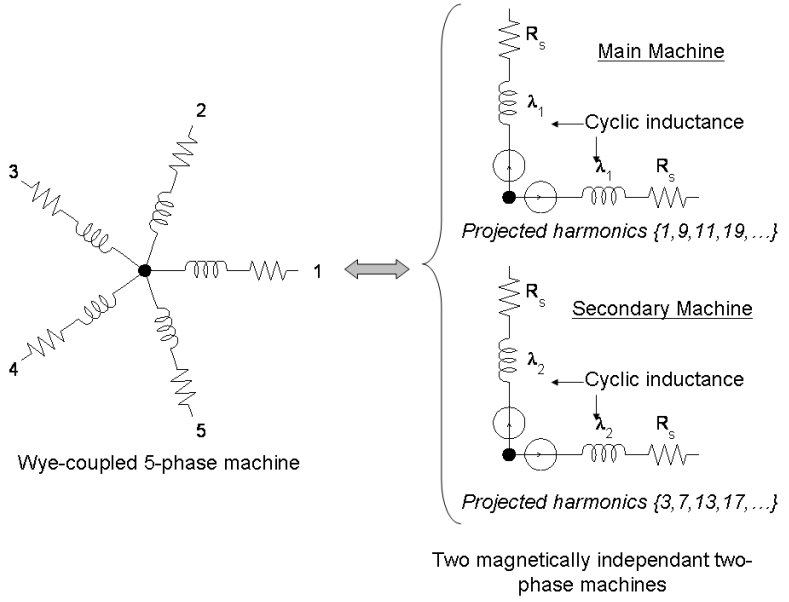

Fig. 1. Multi-machine decomposition for a wye-coupled five-phase machine

The total electromagnetic torque is the sum of the two elementary torques produced by M1 and M2 virtual machines. With a voltage source inverter, a simple and efficient control (called multimachine control) can be implemented: it consists in supplying the machine with currents that contain only the first and third harmonics. Table I summarizes the multimachine control strategy. In this table, $\epsilon_{1}$ and $\epsilon_{3}$ denote the first and third harmonics of the no-load back-emf (at one $\mathrm{rad} / \mathrm{s}$ ). By assuming that M1 and M2 machine currents are perfectly sinusoidal, the multimachine control allows to increase the total electromagnetic torque for given copper losses (base copper losses $P_{b}$ ). Table I quantifies this advantage (in case of Maximum Torque Per Ampere Control): with reference to classical sinusoidal control, the total electromagnetic torque can be enhanced by more than $5 \%$ if the ratio between $\epsilon_{1}$ and $\epsilon_{3}$ is three (ratio obtained with a squarewave signal). To obtain this particular back-emf spectrum, it is possible to conceive a specific magnet layer.

TABLE I

SINUSOIDAL AND MULTIMACHINE CONTROL OF A 5-PHASE MACHINE

\begin{tabular}{|c|c|c|}
\hline Control & Sinus & Multimachine \\
\hline$I_{1}^{\text {ref }}(\mathrm{M} 1)$ & $I_{b}$ & $\frac{\epsilon_{1}}{\sqrt{\epsilon_{1}^{2}+\epsilon_{3}^{2}}} I_{b}$ \\
\hline$I_{3}^{\text {ref }}(\mathrm{M} 2)$ & 0 & $\frac{\epsilon_{3}}{\sqrt{\epsilon_{1}^{2}+\epsilon_{3}^{2}}} I_{b}$ \\
\hline Total Copper losses & \multicolumn{2}{|l|}{$P_{b}$} \\
\hline Total Em Torque & $T_{b}$ & $\frac{1+\left(\frac{\epsilon_{3}}{\epsilon_{1}}\right)^{2}}{\sqrt{1+\left(\frac{\epsilon_{3}}{\epsilon_{1}}\right)^{2}}} T_{b}$ \\
\hline
\end{tabular}

\section{B. Particular pole design review}

For SMPM machines, the adaptation of the magnet layer can be achieved by acting on three main design options:

- the number of magnets per pole (segmented)

- the magnetization of the magnets (radial or parallel)

- the magnet shape.

In a segmented PM machine, each pole is made with several surface-mounted magnet blocks that are positioned in order to obtain particular openings between adjacent blocks. All the magnet blocks are usually of the same type and have the same magnetization direction. The particular openings between the blocks determine the space harmonic content of the magnetomotive force generated by the pole. For a three-phase machine, the design approach is often used to reduce the cogging torque [8], [9]. For example, to choose a magnet arc to pole pitch ratio equal to $2 / 3$ eliminates the first cogging torque harmonic in case of integral-slot winding distribution. This classical magnet layer design can be seen as the most simple pole segmentation. The main drawback of the pole segmentation is the average torque decrease due to the reduction of magnet volume with reference to the equivalent full pole-pitch magnet configuration. As one of the goals of the multi-machine design is to enhance the average torque, the pole segmentation is not investigated.

Halbach array can be seen as an alternative pole segmentation design. With this solution, the pole consists of several magnets of the same span that are magnetised nonradially [10], [11]. The magnetization direction of each block is gradually oriented according to a sinusoidal law. The resulting air gap flux density is thereby all the more sinewave as the number of block per pole is high. Owing to its flux focusing effect, Halbach array significantly improves the magnet volume use with reference to an equivalent full pole-pitch radially magnetized magnet layer [12]. Regarding the multimachine design of the five-phase machine, Halbach array is not suitable because two space harmonics are required (the 1st and the 3rd). Nevertheless it is possible to determine a particular pole segmentation that is close to a Halbach array but with different magnet spans and magnetization angles. This kind of solution already investigated in [3], [13] is not examined in this paper.

In segmented pole or Halbach arrays, the magnets have a classical rectangular shape (the magnet edges are in the radial direction). Another possible shape for the magnet pole is the trapezoid one: when using this solution, the magnet edges are chamfered which contributes to alleviating the torque ripples [4]. Sinusoidal shape or bread shape are shown to be particularly advantageous to reduce the cogging torque [5], [14]. The adverse effect is the same as for pole segmentation: these magnet shapes (sinusoidal or close) reduce the maximal average torque with reference to the equivalent full pole-pitch radially magnetized magnet layer. Therefore, regarding the multimachine design, other magnet shapes must be explored notably because the back-emf must contain significant third harmonic term.

\section{Multi-machine design analysis}

For a five-phase machine, according to the multimachine theory, the design idea consists in looking for a particular magnet shape that induces a back-emf waveform that mainly contains the fundamental and third harmonic. Hence high order harmonics (especially 7, 9, 11 and 13) must be as low as possible to obtain two sinusoidal virtual machine back-emfs. To reach this goal, in [6], for a five-phase machine, a particular trapezoid magnet shape is determined. Regarding the pulsating torque reduction, the obtained results are convincing. However, 
since this trapezoid shape implies a significant reduction of the magnet volume with reference to the full pole-pitch magnet layer $(-26 \%)$, the average torque is reduced $(-16 \%)$.

In this paper, the proposed method is really different because, with the new magnet shape, the average torque must be maintained. To obtain this result, it is decided to realize particular trapezoid notches at the magnet surface. Thus particular space harmonics will be eliminated without reducing the useful air gap flux density. An optimization procedure is necessary to determine the notch characteristics. To perform this task, a fast and accurate analytical field computation is developed.

\section{ANALYTICAL MODEL TO STUDY THE MAGNET SHAPE}

In order to quickly evaluate the magnet pole shape adaptation, a 2D analytical calculation of the air gap flux density is developed from [15]. In this paper, the method is restricted to radially magnetized magnet. The method consists in representing the pole magnets with a set of elementary coils. Table II gives the definitions of the symbols used hereafter.

TABLE II

SYMBOLS DEFINITIONS

\begin{tabular}{|l|c|}
\hline Cylindric coordinates & $(r, \theta)$ \\
\hline Potential vector & $A(r, \theta)$ \\
\hline Harmonic order & $h$ \\
\hline Stator radius (air gap side) & $R_{s}$ \\
\hline Mechanical air gap & $g$ \\
\hline Magnet layer thickness & $h_{m}$ \\
\hline Rotor radius (air gap side) & $R_{r}=R_{s}-g-h_{m}$ \\
\hline Elementary coil current & $I_{c}$ \\
\hline Elementary coils number & $n_{c}$ \\
\hline Elementary coil angular span & $2 \xi$ \\
\hline Elementary coil radial position & $r_{c}$ \\
\hline Elementary coil angular position & $\theta_{c}$ \\
\hline Air permeability & $\mu_{0}$ \\
\hline Remanent flux density & $B_{r}$ \\
\hline Pole pair number & $p$ \\
\hline Slot number per phase per pole & $s_{p p}$ \\
\hline Machine effective length & $L_{m}$ \\
\hline Stator yoke thickness & $t_{y s}$ \\
\hline Rotor yoke thickness & $t_{y r}$ \\
\hline Tooth pitch & $\tau_{s}$ \\
\hline Slot-closing thickness & $t_{s c}$ \\
\hline Slot depth & $d_{s}$ \\
\hline Linear load & $A_{L}$ \\
\hline Current density & $j_{s}$ \\
\hline Notch depth & $\left(h_{1}, h_{2}\right)$ \\
\hline Down notch length & $\left(\tau_{1 b}, \tau_{2 b}\right)$ \\
\hline Down notch center & $\left(\theta_{1 b}, \theta_{2 b}\right)$ \\
\hline Up notch length & $\left(\tau_{1 h}, \tau_{2 h}\right)$ \\
\hline Up notch center & $\left(\theta_{1 h}, \theta_{2 h}\right)$ \\
\hline
\end{tabular}

\section{A. Field due to an elementary coil in an annular air gap}

To perform the analytical calculation of the air gap flux density, the following assumptions relative to the active parts properties are required:

- permeability of the rotor and stator steel is infinite

- magnet permeability equals air permeability $\mu_{0}$

- magnet magnetization is constant.

Geometric simplifications are also necessary:

- the machine axial length is infinite (two-dimensional modeling)

- the local stator slotting is neglected.

Given these assumptions, the vector potential due to an elementary coil centered on $C\left(r_{c}, \theta_{c}\right)$ with an angular span equal to $2 \xi$ can be analytically estimated. According to [15], for an internal rotor machine $\left(R_{r}<R_{s}\right)$, the potential vector for a point $M(r, \theta)$ located in the air gap is (where $I_{c}$ is the coil current):

$$
A(r, \theta)=\frac{\mu_{0} I_{c}}{\pi} \sum_{h=1}^{+\infty} \frac{1}{h} \frac{\sin (h \xi) \sin \left(h\left(\theta+\theta_{c}\right)\right)}{\left(\frac{R_{s}}{R_{r}}\right)^{h}-\left(\frac{R_{r}}{R_{s}}\right)^{h}} f_{h}(r)
$$

with

$$
\begin{aligned}
& \text { - if } r_{c}<r<R_{s} \\
& f_{h}(r)=\left(\frac{R_{s}}{r_{c}}\right)^{h} \frac{r_{c}^{2 h}+R_{r}^{2 h}}{R_{s}^{2 h}-R_{r}^{2 h}}\left[\left(\frac{r}{R_{s}}\right)^{h}+\left(\frac{R_{s}}{r}\right)^{h}\right] \\
& \text { - if } R_{r}<r<r_{c} \\
& f_{h}(r)=\left(\frac{R_{r}}{r_{c}}\right)^{h} \frac{r_{c}^{2 h}+R_{s}^{2 h}}{R_{s}^{2 h}-R_{r}^{2 h}}\left[\left(\frac{r}{R_{r}}\right)^{h}+\left(\frac{R_{r}}{r}\right)^{h}\right]
\end{aligned}
$$

Fig. 2 illustrates this result: the flux lines due to an elementary coil are calculated and drawn according to relation (1).

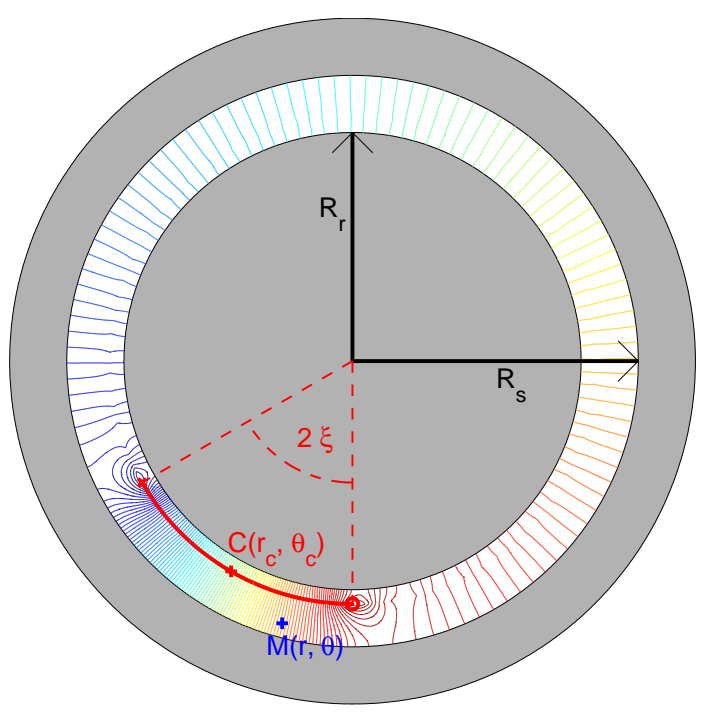

Fig. 2. Air gap flux lines due to an elementary coil

\section{B. Equivalent coil method to represent the magnets}

For surface mounted PM machine, the pole magnets are represented by a set of $n_{c}$ elementary coils, each coil carrying a current $I_{c}$ along the z-axis. In the case of radial magnetization, coil current $I_{c}$ only depends on the remanent flux density $B_{r}$, the magnet height $h_{m}$, air permeability $\mu_{0}$ and the coil 
number $n_{c}$ chosen to represent the magnet:

$$
I_{c}=\frac{1}{n_{c}} \frac{B_{r} h_{m}}{\mu_{0}}
$$

If the magnet edges are in the radial direction (radial shape), the integration along the equivalent coils can be explicitly calculated. The following relationship gives the solution for a point located in the mechanical air gap $\left(R_{r}+h_{m} \leq r \leq R_{s}\right)$ for a magnet centered on angle $\theta_{c}$, with a radial height $h_{m}$ and an angular span $2 \tau_{r}$ :

$$
\begin{aligned}
A(r, \theta)= & \frac{B_{r} \cos \tau_{r}}{\pi} \\
& \sum_{h=1}^{+\infty} \frac{\sin \left(h \tau_{r}\right)}{h}\left[\left(\frac{r}{R_{s}}\right)^{h}+\left(\frac{R_{s}}{r}\right)^{h}\right] \times \\
& \frac{R_{s}^{h}}{R_{s}^{2 h}-R_{r}^{2 h} \sin \left(h\left(\theta+\theta_{c}\right)\right) \times} \\
& \left(\frac{\left(R_{r}+h_{m}\right)^{h+1}-R_{r}^{h+1}}{h+1}+g(h)\right) \\
\text { with } g(h)= & \begin{cases}R_{s} R_{r}^{2} \ln \frac{R_{r}+h_{m}}{R_{r}} & \text { if } h=1 \\
R_{r}^{2 h} \frac{\left(R_{r}+h_{m}\right)^{1-h}-R_{r}^{1-h}}{1-h} & \text { if } h \neq 1\end{cases}
\end{aligned}
$$

If the magnet shape is not radial (for example trapezoid), the integration can not be analytically solved. But, with reference to finite-element analysis, the equivalent coil method is particularly attractive because it is not computationally timeconsuming and easier to implement.

By expanding the whole magnet layer into a set of equivalent coils, it is possible to estimate the air gap flux lines for an equivalent smooth air gap machine (where the slots are removed). Regarding the number of equivalent coils to represent the magnet, according to the study reported in [6], the flux density estimation at the stator periphery quickly converges: for the machines studied in the present paper (and introduced in subsection IV-A), ten equivalent coils are sufficient.

\section{Discussion about the method accuracy}

The proposed approach does not take into account the slotting effect that mainly modifies the flux lines near the stator bore. However, with reference to the equivalent smooth air gap machine, the flux lines are all the more similar that the ratio of the slot opening to the magnetic air gap is small. For the considered surface mounted PM machine with semi-closed slots, since the magnetic air gap includes the mechanical air gap and the magnet thickness, this property is generally accepted. This statement is illustrated by Fig. 3-a and Fig. 3-b: the numerical (when using FEA program FEMM [16]) and analytical flux lines are given for the three-phase machine under consideration in the last part of the paper. One can observe that the air gap flux lines are close. Finally, for the machine considered in this paper, the effects of slotting are relatively small for most aspects of performance except cogging torque.

To take into account the slotting, a permeance function can be introduced from an extrapolation of the flux lines in the

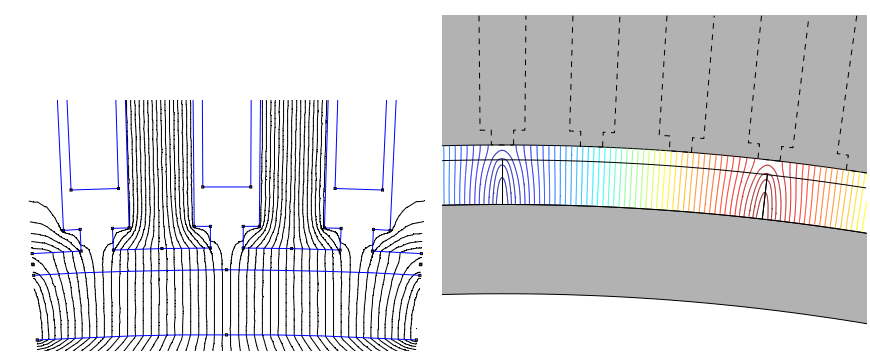

(a) Numerical estimation (FEA pro- (b) Analytical estimation (equivalent gram FEMM) coil method)

Fig. 3. Flux lines calculations for the reference 3-phase machine

slots [17], [18]: the cogging torque can be estimated with this method [19]. Recent studies focus on the subdomain approach that gives an analytical solution for the potential vector in the air gap but also in the slots [20], [21] or in the magnets in case of inset magnets [22].

\section{APPLICATION TO LOW-SPEED NAVAL PROPULSION MACHINE}

\section{A. Machine characteristics}

In order to evaluate the magnet shape adaptation, a low speed SMPM machine for marine propulsion (2MW@ $150 \mathrm{rpm}$ ) is considered. Table III gives the electromagnetic characteristics of this machine. The main design objective is the reduction of the ripple torques. A fault tolerant ability is also aimed for. A five-phase machine is thus preferred to a three-phase one [1], [2]. A full pole-pitched winding is chosen in order to maximize the winding factor thus improving the torque density. Furthermore the cogging torque is reduced when the phase is increased in case of full pole-pitched winding.

TABLE III

MAIN ELECTROMAGNETIC CHARACTERICS OF THE PROPULSION MACHINE

\begin{tabular}{|c|c|}
\hline Pole pair number & $p=28$ \\
\hline Slot number per phase per pole & $s_{p p}=1$ \\
\hline Effective length & $L_{m}=1.125 \mathrm{~m}$ \\
\hline Stator diameter & $2 R_{s}=1.6 \mathrm{~m}$ \\
\hline Stator yoke thickness & $t_{y s}=0.05 \mathrm{~m}$ \\
\hline Mechanical airgap & $g=0.005 \mathrm{~m}$ \\
\hline Rotor yoke thickness & $t_{y r}=0.03 \mathrm{~m}$ \\
\hline Magnet layer thickness & $h_{m}=0.015 \mathrm{~m}$ \\
\hline Remanent flux density & $B_{r}=1.17 \mathrm{~T}$ \\
\hline Magnet volume & $83.5 \times 10^{-3} \mathrm{~m}^{3}$ \\
\hline Slot width $\left(\tau_{s}\right.$, tooth pitch) & $0.5 \tau_{s}$ \\
\hline Slot width opening & $0.25 \tau_{s}$ \\
\hline Slot-closing thickness & $t_{s c}=0.005 \mathrm{~m}$ \\
\hline Slot depth & $d_{s}=0.065 \mathrm{~m}$ \\
\hline Active copper volume & $95.6 \times 10^{-3} \mathrm{~m}^{3}$ \\
\hline End-winding copper volume & $6.0 \times 10^{-3} \mathrm{~m}^{3}$ \\
\hline Linear load & $A_{L}=3.75 \times 10^{4} \mathrm{~A} / \mathrm{m}$ \\
\hline Current density & $j_{s}=2.22 \times 10^{6} \mathrm{~A} / \mathrm{m}^{2}$ \\
\hline
\end{tabular}


In order to evaluate the potential advantages of the magnet shape optimization, for the geometric specifications given in table III, three configurations of the motor will be considered:

- the three-phase configuration where the rotor is made with full pole-pitch magnet

- the base five-phase configuration where the rotor is made with full pole-pitch magnet

- the new five-phase configuration where the rotor shape is optimized according to the procedure described in the next subsection.

The three-phase and five-phase configurations are equipped with a full pole-pitch integral-slot winding. As the end-turn winding size mainly depends on the pole number and the machine diameter, one can assume that the three machines have the same copper volume and the same base copper losses (since they work with the same linear load and current density).

\section{B. Optimization problem}

In order to adapt the air gap flux density spectrum to the multimachine design, a procedure that optimizes small trapezoid notches at the surface of the pole magnets is performed. In order to keep the symmetry of the back-emf waveform (to avoid even space harmonics), the pole magnet symmetry must be conserved. Consequently, if a notch is made at a demi-pole, a symmetrical notch must be made at the other demi-pole.

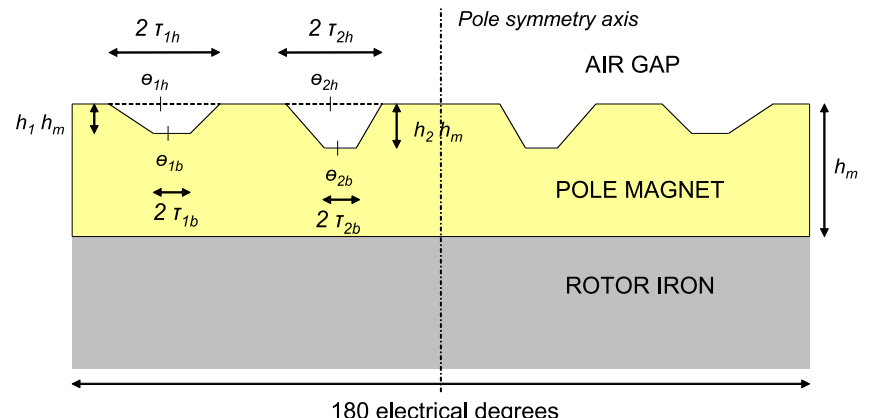

Fig. 4. Optimization variables

Fig. 4 illustrates the geometric notches parameters under optimization. The set of geometric parameters in Fig. 4 defines the optimization variable $x$ :

$$
\left.\begin{array}{cccccccccc}
x= \\
h_{1} & \theta_{1 b} & \tau_{1 b} & \theta_{1 h} & \tau_{1 h} & h_{2} & \theta_{2 b} & \tau_{2 b} & \theta_{2 h} & \tau_{2 h}
\end{array}\right]_{(4)}^{T}
$$

Due to geometric reasons, the optimization parameters must be lower and upper bounded according to the following relation:

$$
\left\{\begin{array}{l}
0 \leq h_{1} \leq 0.5 \\
0 \leq \theta_{1 b} \leq 90 \\
0 \leq \tau_{1 b} \leq 90 \\
0 \leq \theta_{1 h} \leq 90 \\
0 \leq \tau_{1 h} \leq 90 \\
0 \leq h_{2} \leq 0.5 \\
0 \leq \theta_{2 b} \leq 90 \\
0 \leq \tau_{2 b} \leq 90 \\
0 \leq \theta_{2 h} \leq 90 \\
0 \leq \tau_{2 h} \leq 90
\end{array} \quad \Longleftrightarrow \quad L_{b} \leq x \leq U_{b}\right.
$$

Concerning the notch depth $\left(h_{1}\right.$ and $\left.h_{2}\right)$, the maximal value is set to half the base magnet layer thickness $h_{m}$ because it can be inferred that too deep a notch would excessively reduce the flux density. Furthermore demagnetization issues can occur if the magnet thickness is reduced too much.

Linear inequality constraints are defined from the following requirements:

- down notch length $\left(\tau_{1 b}\right.$ and $\left.\tau_{2 b}\right)$ must be smaller than up notch length $\left(\tau_{1 h}\right.$ and $\left.\tau_{2 h}\right)$ for manufacturing reason

- no overlapping between the two notches to facilitate the tracking of the optimal solution (however two notches can merge to one during the optimization procedure).

Matrix $A$ and vector $b$ for linear inequality constraints are then defined as follows:

$$
\left\{\begin{array}{l}
\tau_{1 h}-\theta_{1 h} \leq 0 \\
\tau_{1 b}-\theta_{1 b} \leq 0 \\
\tau_{1 b}-\tau_{1 h} \leq 0 \\
\tau_{2 b}-\tau_{2 h} \leq 0 \\
\theta_{1 b}+\tau_{1 b}-\theta_{2 b}+\tau_{2 b} \leq 0 \\
\theta_{1 h}+\tau_{1 h}-\theta_{2 h}+\tau_{2 h} \leq 0 \\
\theta_{2 b}+\tau_{2 b} \leq 90 \\
\theta_{2 h}+\tau_{2 h} \leq 90
\end{array} \Longleftrightarrow A x \leq b\right.
$$

The main design goal is to adapt the magnet layer characteristics to obtain sinusoidal back-emf for the two virtual machines $M 1$ and $M 2$. The choice of the objective function and the non linear constraint determines the way to formulate this objective. The objective function to minimize is given by equation (7):

$$
f(x)=B_{7}(x)^{2}+B_{9}(x)^{2}+B_{11}(x)^{2}+B_{13}(x)^{2}
$$

The objective function focuses on the reduction of particular flux density harmonics: $B_{9}$ and $B_{11}$ relative to virtual machine $M 1$ and $B_{7}$ and $B_{13}$ relative to virtual machine $M 2$. The objective function must be minimized under a constraint that guarantees a sufficient level of flux density fundamental for virtual machines $M 1\left(B_{1}\right)$ and $M 2\left(B_{3}\right)$. This sufficient level of flux density is determined so that the optimized machine produces an average electromagnetic torque less as high as 95\% the average electromagnetic torque obtained with the full pole-pitch magnet configuration. This new maximal average electromagnetic torque is supposed to be obtained in case of multimachine control of the five-phase machine. The maximal electromagnetic torque directly relates to the 1 st and $3 \mathrm{rd}$ harmonic terms of the flux density denoted $B_{1,0}$ and $B_{3,0}$. 
Finally the non linear constraint is expressed as follows:

$$
-c(x)=B_{1}(x)^{2}+B_{3}(x)^{2}-0.95\left(B_{1,0}^{2}+B_{3,0}^{2}\right) \geq 0
$$

The final optimization problem is summarized in equation (9) based on relations (5),(6), (7) and (8):

$$
\min _{x} f(x) \quad\left\{\begin{array}{l}
c(x) \leq 0 \\
A x \leq b \\
L_{b} \leq x \leq U_{b}
\end{array}\right.
$$

This optimization problem is solved with fmincon function from Matlab/Simulink optimization toolbox. One can note that a procedure that consists in calculating a high number of magnet shapes and after selecting the better solutions with regards to the objective and constraints would be difficult to compute because the variables are continuous and not discrete. In practice, equation (3) is used to calculate the base flux density at the beginning of the procedure. At each iteration, new notches are defined. The flux density due to magnets which have the notch shapes is calculated with the equivalent coil method. This flux density is subtracted from the base flux density in order to obtain the machine flux density. With this approach, the equivalent coil method is applied to the small notch volume, thus virtually eliminating the sensitivity to the number of equivalent coils and making the convergence easier.

The obtained solution is depicted in Fig. 5. The reduction of the magnet volume is about $4 \%$ referring to the full polepitch magnet rotor. It should be noted that magnets with a single notch per demi-pole were investigated at first. An optimum solution was found but it appeared that the reduction of the objective function (7) was not satisfactory enough: the reduction of the pulsating torques was not sufficient.

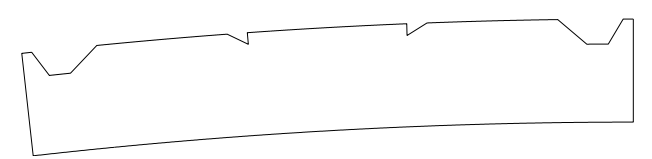

Fig. 5. Optimum trapezoid notches

The final optimum solution (in Fig. 5) is validated with FEA program FEMM [16]. Fig. 6 compares the air gap flux lines according to FEA with the ones according to the analytical method. The lines are quite similar particularly in the interpolar area where the deep notches are. Fig. 7 focuses on the no load back-emf comparison. The numerical back-emf is calculated via the flux density integration over the slots area. Fig. 7-a shows that the numerical and analytical waveforms are close: the notch effects are the same. The numerical amplitudes are lower than the analytical ones because the slotting reduces the total flux per pole. In Fig. 7-b, it can be seen that the 7th, 9th, 11th and 13th harmonics are almost cancelled in both numerical and analytical signals.

\section{Performance estimations with the optimized magnet shape}

In this subsection, the performance improvements with the optimized magnet shape are estimated with the analytical method and FEA. It should be noted that the comparison between the analytical model and FEA is restricted to air

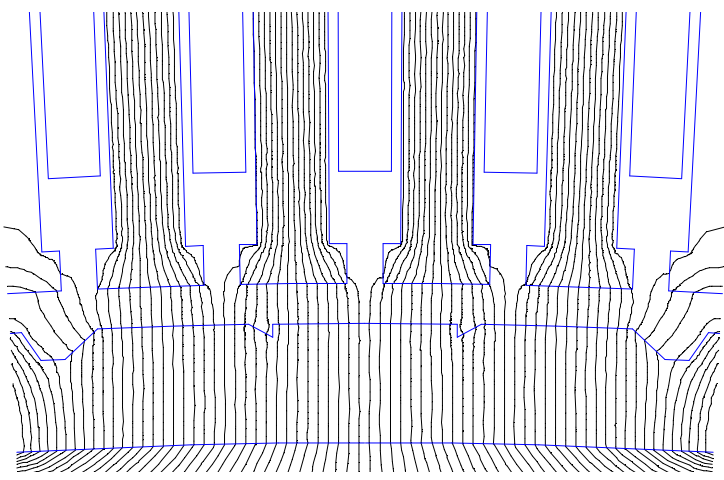

(a) Numerical estimation (FEA program FEMM)

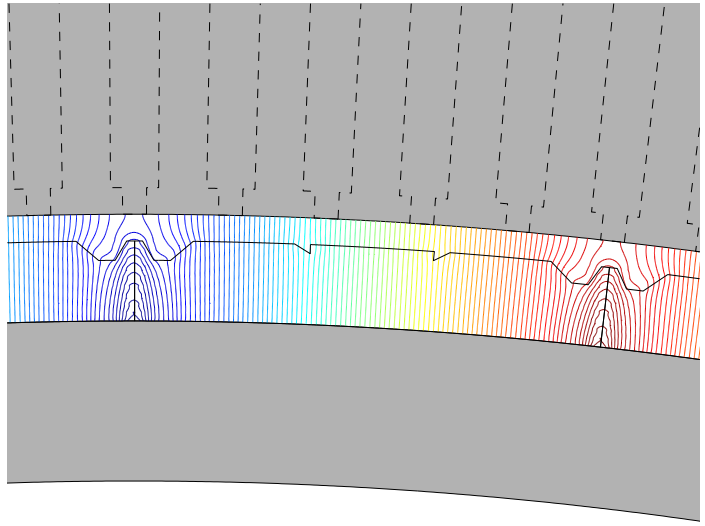

(b) Analytical estimation (equivalent coil method)

Fig. 6. Flux lines obtained with the optimized magnet shape

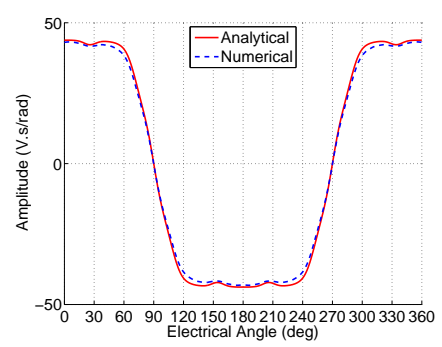

(a) Waveform

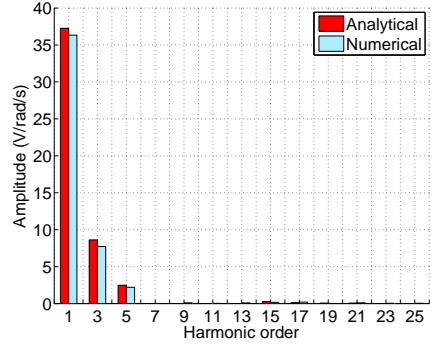

(b) Fourier series decomposition
Fig. 7. Analytical and numerical no load back-emf estimations

gap flux and back-emf estimations. Radial forces are not calculated because, for the considered machines, the winding is integral-slot that does not induce magnetomotive force subharmonics. In contrast, if the winding was fractional-slot, it would be necessary to calculate the radial forces: in this case, the magnetomotive force subharmonics can induce vibrations which possibly cancel the benefits of the new magnet shape in terms of the reduction of vibrations.

Fig. 8 shows the virtual machine back-emfs for both reference and optimized five-phase machines. With the new rotor shape, the back-emfs of the two 2-phase virtual machines (M1 and M2) are sinewave: this is due to the reductions of harmonics 7, 9, 11 and 13 in the back-emf spectrum (as targeted by the optimization procedure). This reduction does not adversely 
affect the torque density because the fundamental and the third harmonic amplitudes are almost unchanged with the new shape: reduction of $1.5 \%$ for the fundamental (from 37.9 to $37.3 \mathrm{~V} / \mathrm{rad} / \mathrm{s}$ ) and reduction of $13 \%$ for third harmonic (from 9.9 to $8.6 \mathrm{~V} / \mathrm{rad} / \mathrm{s}$ ). One can note that, for the fundamental, the reduction is lower than the magnet volume decrease $(-4 \%)$. These results comply with the multimachine design objectives described in section II-A.
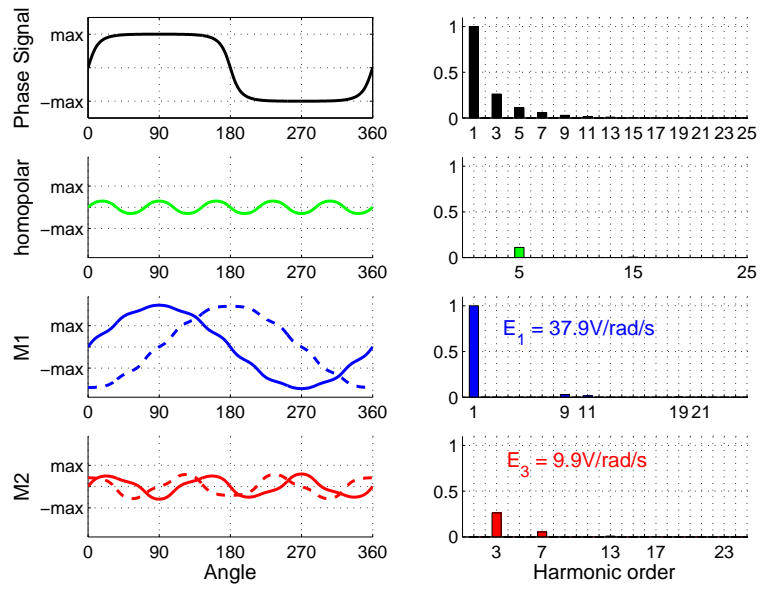

(a) Reference 5-phase machine
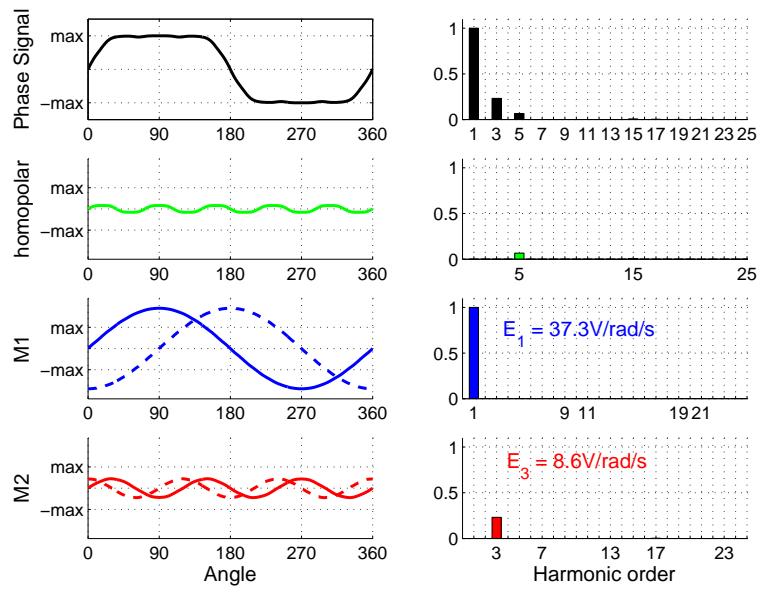

(b) Optimized 5-phase machine

Fig. 8. Virtual machine back-emfs for the reference and optimized 5-phase machines (with analytical method)

These sinusoidal back-emfs enable the optimized machine to provide a smooth electromagnetic torque. To check this property, given the initial three-phase machine, the reference five-phase machine and the optimized five-phase machine, the electromagnetic torques are calculated with sinusoidal control and with multimachine control for the five-phase machine. When using third harmonic current injection as explained in part II-A, it is important to remember that the third hamonic cannot be used to generate additional torque with a wyecoupled three-phase machine. All the results are obtained for the same copper losses in steady state operation when using an average model of the converter (only fundamental and possibly third harmonic in the current). Fig. 9-a gives the electromagnetic torques obtained by considering the analytical back-emf. The pulsating torque reduction with the new magnet shape is clear. Fig. 9-b gives the electromagnetic torques obtained with FEA: the torque is calculated by integrating the Lorentz forces acting on the stator currents. These numerical results confirm the substantial reduction of the pulsating torque predicted by the analytical approach.

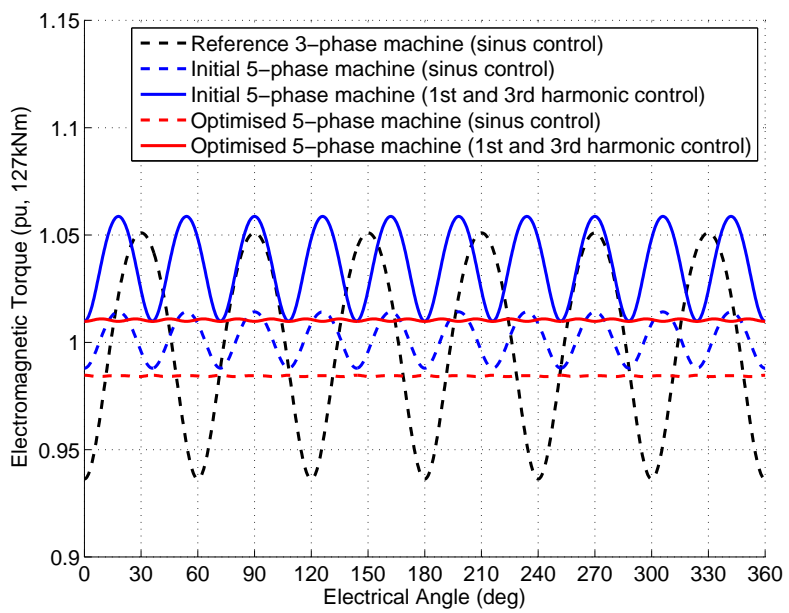

(a) Analytical

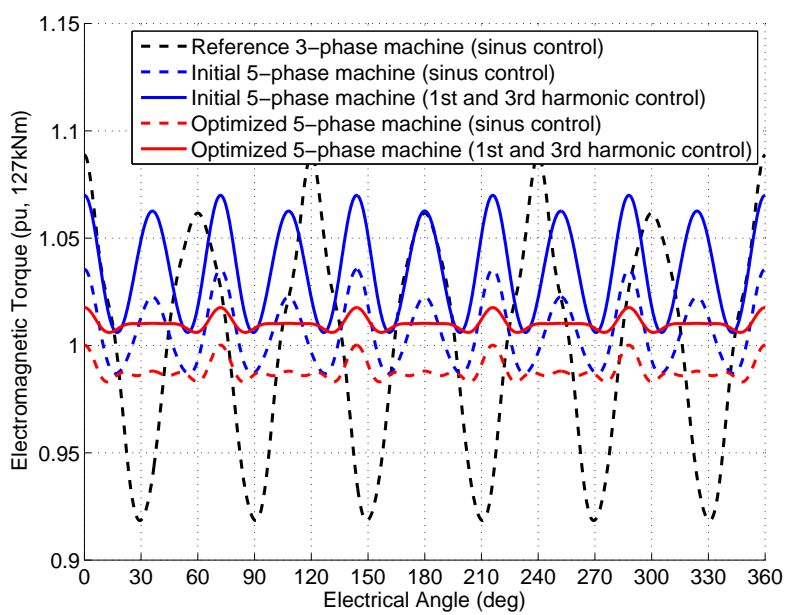

(b) Numerical (Lorentz force integration)

Fig. 9. Electromagnetic torque for the same copper losses

The results given by Fig. 9-a and Fig. 9-b are quantified by tables IV and $\mathrm{V}$ that indicate the numerical values of the average and pulsating torques. According to the analytical method (see table IV), when using the new magnet shape, the pulsating torque is virtually eliminated: it is reduced by more than 100 times referring to the three-phase machine and by more than 20 times referring to the initial fivephase machine. According to the numerical analysis (see table $\mathrm{V})$, the pulsating torque reduction is less important but still significant: it is reduced by more than 10 times referring to the three-phase machine and by more than 3 times referring to the initial five-phase machine. Regarding the average torques, the same conclusion can be drawn from the two methods: with the multimachine control strategy, the optimized five- 
phase machine can provide a torque higher than the reference three-phase machine (about 1\%) whereas the magnet volume is reduced $(4 \%)$. This characteristic stigmatizes a better use of the magnet material.

TABLE IV

ANALYTICAL RESULTS CONCERNING THE TORQUE IMPROVEMENTS $\left(T_{0}=127 \mathrm{kNm}\right.$ AND $\left.t_{0}=0.12 T_{0}=14.6 \mathrm{kNm}\right)$

\begin{tabular}{|l|c|c|c|}
\hline Machine & Control & $\begin{array}{c}\text { Average } \\
\text { Torque }\end{array}$ & $\begin{array}{c}\text { Torque } \\
\text { Ripples }\end{array}$ \\
\hline 3-phase, reference & sinus & $T_{0}$ & $t_{0}$ \\
\hline 5-phase, initial & sinus & $T_{0}$ & $0.23 t_{0}$ \\
& multimachine & $1.04 T_{0}$ & $0.43 t_{0}$ \\
\hline \multirow{2}{*}{ 5-phase, optimised } & sinus & $0.98 T_{0}$ & $0.01 t_{0}$ \\
& multimachine & $1.01 T_{0}$ & $0.01 t_{0}$ \\
\hline
\end{tabular}

TABLE V

FEA RESULTS CONCERNING THE TORQUE IMPROVEMENTS $\left(T_{0}=127 \mathrm{kNm}\right.$ AND $\left.t_{0}^{\prime}=0.17 T_{0}=21.6 \mathrm{kNm}\right)$

\begin{tabular}{|l|c|c|c|}
\hline Machine & Control & $\begin{array}{c}\text { Average } \\
\text { Torque }\end{array}$ & $\begin{array}{c}\text { Torque } \\
\text { Ripples }\end{array}$ \\
\hline 3-phase, reference & sinus & $T_{0}$ & $t_{0}^{\prime}$ \\
\hline \multirow{2}{*}{ 5-phase, initial } & sinus & $1.01 T_{0}$ & $0.28 t_{0}^{\prime}$ \\
& multimachine & $1.04 T_{0}$ & $0.38 t_{0}^{\prime}$ \\
\hline \multirow{2}{*}{ 5-phase, optimised } & sinus & $0.99 T_{0}$ & $0.10 t_{0}^{\prime}$ \\
& multimachine & $1.01 T_{0}$ & $0.07 t_{0}^{\prime}$ \\
\hline
\end{tabular}

The optimization procedure aims to reduce the ripple torques. Therefore it is important to check if the cogging torque is mitigated with the new machine. Fig. 10 shows analytical and numerical estimations of the cogging torque for the reference three-phase machine, the initial five-phase machine and the optimized five-phase machine. The analytical estimation is taken from [19] (by introducing a permeance function to take into account the slotting as mentioned in subsection III-C) and the numerical estimation is computed with FEMM (by integrating Maxwell's stress tensor). The two methods confirm the expected reduction of the cogging torque with the five-phase machines (due to larger number of slots per pole). For the new magnet shape, both the analytical and numerical methods estimate a lower cogging torque which can be explained by the reduction of the fifth harmonic term of the air gap flux density. Furthermore the two methods show that, for the five-phase machines, the cogging torque amplitude (indicated in the legends of the Fig. 10-a and Fig. 10-b) is lower than the pulsating torque amplitude (given in tables IV and V).

Another critical point that must be considered is the demagnetization issue. Since the magnet thickness is reduced where the notches are, local demagnetization can occur. In order to evaluate this possibility, for the optimized machine, the air gap flux density along the magnet surface of a pole is calculated with FEA in load and no load conditions: the results are reported in Fig. 11. For the considered magnets, the knee flux density is around $0.1 \mathrm{~T}$ (which corresponds to a limiting magnetizing force of about $-850 \mathrm{kA} / \mathrm{m}$ ). Fig. 11 confirms the

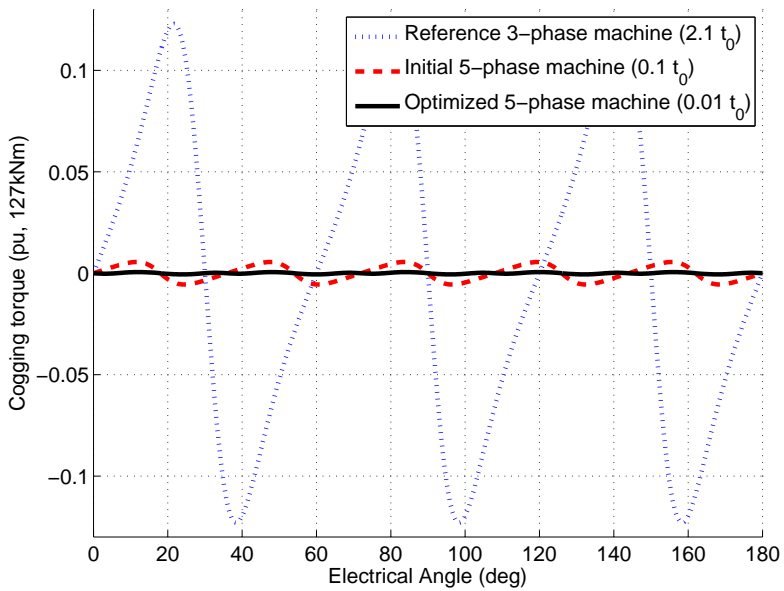

(a) Analytical

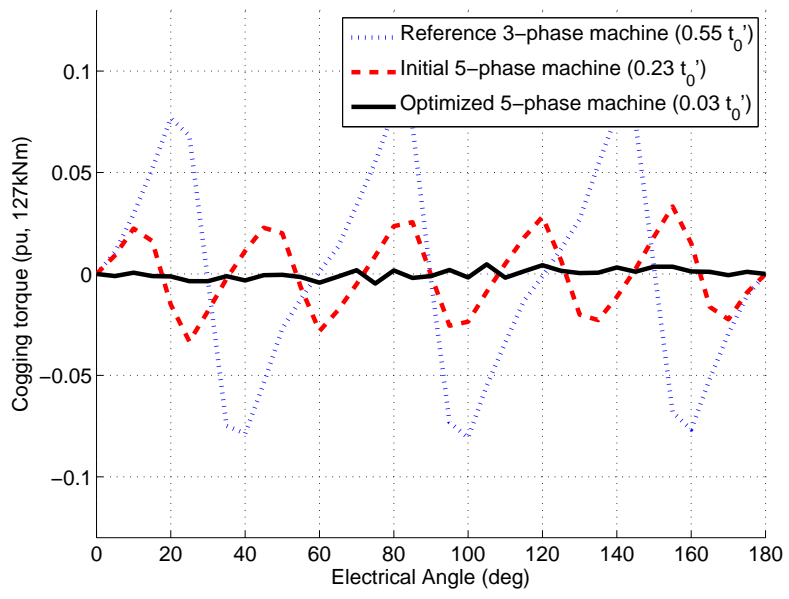

(b) Numerical

Fig. 10. Cogging torque estimations for the 3-phase and 5-phase machines

demagnetization possibility in the notch area (particularly for the deeper notches, near the interpolar boundary). However the estimated flux density is higher than the knee value $(0.1 \mathrm{~T})$ thus meaning that, according to the modelling, the demagnetization does not occur.

\section{CONCLuSion}

Dealing with the design of a five-phase low speed SMPM machine, this paper demonstrates the possibility of adapting the magnet shape in order to reduce the pulsating torques. This investigation is carried out with a two-dimensional analytical calculation of the air gap flux density: the so-called equivalent coils method is convenient to analyse large air gap machines with semi-closed slots where the effects of slotting is relatively small for most aspects of performance (except cogging torque). With reference to FEA analysis, this analytical method is not computationally time-consuming. Consequently this method facilitates the study of particular magnet shapes taking into account the multimachine design: a procedure that optimizes small trapezoid notches at the surface of the pole magnets is thereby developed. With reference to a rotor made with full pole-pitch magnet, the obtained optimal 


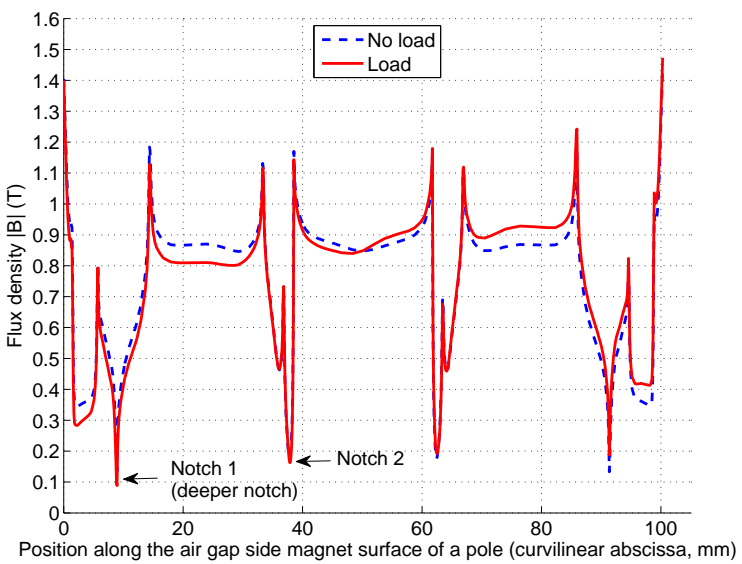

Fig. 11. Air gap flux density along the magnet surface of a pole

solution enables a significant reduction of the pulsating torque that does not adversely affect the torque density. Indeed, for the corresponding three-phase machine, the average torque of the optimized five-phase machine can be potentially higher if the multimachine control is implemented. Finally, to improve the evaluation of the benefits of the proposed approach, further studies are necessary such as estimating the magnet losses and taking into account the slot effects (for small air gap machine). These objectives can be achieved by developing a more accurate analytical approach (as in [21]). Regarding the experimental side, the manufacturing of a demonstrator is necessary especially to evaluate the feasibility of the magnet notches without degrading the magnetization properties.

\section{ACKNOWLEDGMENT}

The author would like to thank S. Djebarri from the Research Institute of Naval Academy for his help with computing the machines with FEA program FEMM and F. Byrne from the French Naval Academy for her English proofreading.

\section{REFERENCES}

[1] E. Levi, "Multiphase electric machines for variable-speed applications," Industrial Electronics, IEEE Transactions on, vol. 55, no. 5, pp. 1893 1909, 2008

[2] X. Kestelyn and E. Semail, "A vectorial approach for generation of optimal current references for multiphase permanent-magnet synchronous machines in real time," Industrial Electronics, IEEE Transactions on, vol. 58, no. 11, pp. $5057-5065$, nov. 2011.

[3] F. Scuiller, E. Semail, J.-F. Charpentier, and P. Letellier, "Multi-criteria based design approach of multiphase permanent magnet low speed synchronous machines," IET Electric Power Applications, vol. 3, no. 2, pp. 102-110, 2009.

[4] J. D. L. Ree and N. Boules, "Magnet shaping to reduce voltage harmonics in pm machines with surface mounted magnets," IEEE Transactions on Energy Conversion, vol. 6, no. 1, pp. 155-161, 1991.

[5] S.-M. Jang, H.-I. Park, J.-Y. Choi, K.-J. Ko, and S.-H. Lee, "Magnet pole shape design of permanent magnet machine for minimization of torque ripple based on electromagnetic field theory," Magnetics, IEEE Transactions on, vol. 47, no. 10, pp. 3586 -3589, oct. 2011.

[6] F. Scuiller, "Study of a particular magnet shape for a five-phase surface-mounted pm machine," in Electric Machines Drives Conference (IEMDC), 2013 IEEE International, 2013, pp. 40-45.

[7] E. Semail, A. Bouscayrol, and J.-P. Hautier, "Vectorial formalism for analysis and design of polyphase synchronous machines," Eur. Phys. J., vol. AP 22, pp. 207-220, 2003
[8] R. Lateb, N. Takorabet, and F. Meibody-Tabar, "Effect of magnet segmentation on the cogging torque in surface-mounted permanentmagnet motors," IEEE Transactions on Magnetics, vol. 42, no. 3, pp. 442-445, March 2006.

[9] M. Ashabani and Y.-R. Mohamed, "Multiobjective shape optimization of segmented pole permanent-magnet synchronous machines with improved torque characteristics," Magnetics, IEEE Transactions on, vol. 47 , no. 4 , pp. $795-804$, april 2011.

[10] K. Halbach, "Design of permanent magnets multipole with oriented rare earth cobalt material," Nucl. Instrum. Methods, vol. 169, pp. 1-10, 1980.

[11] Z. Xia, Z. Zhu, and D. Howe, "Analytical magnetic field analysis of halbach magnetized permanent-magnet machines," Magnetics, IEEE Transactions on, vol. 40, no. 4, pp. 1864 - 1872, july 2004.

[12] Z. Zhu and D. Howe, "Halbach permanent magnet machines and applications: a review," IEE Proc.-Electr. Power Appl., vol. 148, no. 4, pp. 299-308, July 2001.

[13] F. Scuiller, E. Semail, J.-F. Charpentier, and S. Clénet, "Comparison of conventional and unconventional 5-phase pm motor structures for naval applications," IASME Transactions Issue 2, vol. 1, pp. 365-370, 2004.

[14] H. Hong and J. Yoo, "Shape design of the surface mounted permanent magnet in a synchronous machine," Magnetics, IEEE Transactions on, vol. 47 , no. 8, pp. $2109-2117$, aug. 2011.

[15] K. Rasmussen, J. Davies, T. Miller, M. McGelp, and M. Olaru, "Analytical and numerical computation of air-gap magnetic fields in brushless motors with surface permanent magnets," Industry Applications, IEEE Transactions on, vol. 36, no. 6, pp. 1547 - 1554, nov/dec 2000.

[16] D. Meeker, "Finite element method magnetics, version 4.2, users manual," FEMM official website, October 2010. [Online]. Available: http://www.femm.info/Archives/doc/manual42.pdf

[17] Z. Q. Zhu and D. Howe, "Instantaneous magnetic field distribution in brushless permanent magnet dc motors, part iii: Effect of stator slotting," IEEE Transactions on Magnetics, vol. 29, no. 1, pp. 143-151, January 1993.

[18] A. B. Proca, A. Keyhani, A. El-Antably, W. Lu, and M. Dai, "Analytical model for permanent magnets motors with surface mounted magnets," IEEE Transactions on Energy Conversion, vol. 18, no. 3, pp. 386-391, September 2003.

[19] Z. Q. Zhu and D. Howe, "Analytical prediction of the cogging torque in radial-field permanent magnet brushless motors," IEEE Transactions on Magnetics, vol. 28, no. 2, pp. 1371-1374, March 1992.

[20] Z. Zhu, L. Wu, and Z. Xia, "An accurate subdomain model for magnetic field computation in slotted surface-mounted permanent-magnet machines," Magnetics, IEEE Transactions on, vol. 46, no. 4, pp. 1100 -1115 , april 2010.

[21] T. Lubin, S. Mezani, and A. Rezzoug, "2-d exact analytical model for surface-mounted permanent-magnet motors with semi-closed slots," Magnetics, IEEE Transactions on, vol. 47, no. 2, pp. $479-492$, feb. 2011.

[22] A. Rahideh and T. Korakianitis, "Analytical magnetic field calculation of slotted brushless permanent-magnet machines with surface inset magnets," Magnetics, IEEE Transactions on, vol. 48, no. 10, pp. 2633 -2649 , oct. 2012.

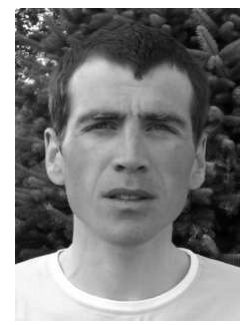

Franck Scuiller (M'11) was born in Brest, France in 1977. He received the Electrical Engineering degree (M.Sc. degree) from ENSIEG, INPG (Grenoble National Polytechnic Institute) in 2001 and the Ph.D. degree from Arts et Metiers ParisTech in 2006. In 2007, he was a lecturer in French Naval Academy. From 2008 to 2011, he was a technical project manager in warship electric power systems for DCNS company (Lorient, France). Since September 2011, he is an Associate Professor in Electrical Engineering in the French Naval Academy. His research interest includes electromechanical conversion in marine environment with a particular focus on marine current turbine generation and multi-phase machine for ship propulsion. He also works on ship grid modeling and simulation. 